\title{
INFLUÊNCIAS PARENTAIS NA SAÚDE MENTAL DAS CRIANÇAS NA FASE DA SEGUNDA INFÂNCIA
}

\author{
THE INFLUENCE OF PARENTING ON EARLY CHILDHOOD HEALTH
}

\author{
Suelen Elias Pereira ${ }^{1}$, Carla Simon ${ }^{2}$, Cristina Adriana Rodrigues Kern ${ }^{3}$, Karin Martins \\ Gomes $^{4}$
}

\begin{abstract}
RESUMO
Esta pesquisa teve como objetivo analisar a relação existente entre limites, modelos educacionais e psicopatologias parentais; sendo realizada em um centro de educação infantil de Forquilhinha - SC e participaram da pesquisa 16 mães e uma avó, as quais tinham filhos/neto na fase da segunda infância. Trata-se de um estudo qualitativo e para a coleta de dados foi utilizado entrevista semiestruturada. Os dados foram analisados com base na análise de conteúdo e os resultados indicam que a cultura de cada família é diferente, a grande maioria das mães estabelece limites e tem consciência que o modelo de educação utilizado influencia no comportamento dos filhos, tanto atual quanto futuramente, as mães diagnosticadas com transtorno mental possuem mais dificuldades em colocar limites e regras e os filhos possuem um comportamento mais difícil, estas mães acreditam que pode haver alguma complicação futura para os filhos em virtude de seu transtorno.

Palavras-chave: Estilo Educacional Parental; Psicopatologia Parental; Limites.
\end{abstract}

\begin{abstract}
The purpose of this study was to analyze the relationship between limits, educational models and parental psychopathology. This research was held at an early childhood education center in the city Forquilhinha - SC; the participants inclued 16 mothers and one grandmother, which had children / grandchild at the early childhood stage. This is a qualitative study and data was collected using semi-structured interview. The data was analyzed based on content analysis which the results indicated that the culture of each family is different and the most mothers establish limits. However, they were aware that the education guidelines used influence in the behavior of their children not only in present moment, but also in their future. Mothers diagnosed with mental disorder have more difficulties in setting limits and rules, therefore presenting challenging behavior in their children. Also, these mothers believe that their children might have some future complications because of their disorder.

Keywords: Educational Parenting Style; Parental psychopathology; Limits.

\footnotetext{
${ }^{1}$ Acadêmica do Curso de Psicologia da Universidade do Extremo Sul Catarinense - UNESC.

${ }^{2}$ Psicóloga Residente do Programa de Residência Multiprofissional da Universidade do Extremo Sul Catarinense - UNESC.

${ }^{3}$ Professora Mestre do curso de Psicologia da Universidade do Extremo Sul Catarinense - UNESC.

${ }^{4}$ Professora Doutora do curso de Psicologia da Universidade do Extremo Sul Catarinense - UNESC. E-mail: karin@unesc.net.
} 


\section{INTRODUÇÃO}

A segunda infância, período entre três e seis anos de idade, é uma fase de muitas mudanças para a criança, é um momento de novos conhecimentos e descobertas, esta fase também é chamada de pré-escolar e segundo Piaget a criança está no estágio pré-operatório que é, quando o pensamento simbólico e a capacidade representacional começam se desenvolver.

Até os três anos de idade, as crianças desenvolvem muitas atividades motoras e não motoras e, na medida em que vai se desenvolvendo, as atividades vão ficando mais elaboradas (BEE, 1997). À medida em que a criança aumenta o controle sobre o próprio corpo, começa a desenvolver com mais facilidade suas necessidades pessoais e as interações sociais constituem parte importante nesse momento do desenvolvimento, contribuindo na preparação da alfabetização, memória e inteligência (PAPALIA; OLDS; FELDMAN, 2006).

Nesta fase do desenvolvimento cabe destacar os estilos parentais de educação. Dentro deste contexto, o limite está muitas vezes intrínseco, a criança precisa saber especificamente quais são as regras da família em que está inserida, pois inicialmente ela não nasce com uma consciência do que é certo e errado e cabe aos pais passar as regras, valores e limites para que a criança tenha entendimento de como conviver em sociedade.

A partir das pesquisas de Baumrind (1966 apud WEBER et al, 2004) propõe três estilos diferentes de controle parental que são intitulados pais autoritários, permissivos e autoritativos (ou democráticos).

É provável que o estilo parental democrático seja mais efetivo porque esses pais estabelecem claramente as regras mostrando aos filhos o que esperam deles, com expectativas sensatas e reais para a criança. Nos lares com pais autoritários a criança é controlada rigorosamente e geralmente não pode fazer escolhas, nas famílias permissivas recebe tão pouco controle que pode ficar insegura com relação ao fazer o que é certo. (PAPALIA; FELDMAN, 2013).

Os estilos parentais possuem relação direta com a saúde mental dos filhos. Alguns autores têm estudado também a relação entre as psicopatologias infantis e os modelos de educação adotados pelos pais.

Outra questão importante que pode afetar o comportamento da criança é a relação dos próprios pais entre si, como desentendimentos conjugais ou a existência de transtorno mental 
em um dos pais, tendo como consequência o surgimento de sintomas de transtorno ou comportamento internalizante ou externalizante na criança.

Para Marcelli e Cohen (2010) está claro que a família tem um papel muito importante na vida da criança, tanto no desenvolvimento saudável, quanto no aparecimento das psicopatologias. A família, muitas vezes, aparece como o principal fator causador destas condições.

Entende-se por transtornos externalizantes aqueles comportamentos marcados por atos agressivos e com quebra de regras como no transtorno de conduta e transtorno desafiador opositor, por exemplo. Já os transtornos internalizantes são caracterizados por comportamentos mais interiorizados tal como: depressão, ansiedade, fobias ou outros relacionados (PESCE, 2009).

Há também os comportamentos externalizantes que são caracterizados pela impulsividade, agressividade, agitação e posicionamento desafiador e os comportamentos internalizantes que acabam, muitas vezes, privando o indivíduo de relacionar-se com as pessoas do meio, mostrando atitudes que são marcadas, principalmente, pelo retraimento (BOLSONI-SILVA; MARTURANO et al, 2006).

Estudos tem relacionado estilos parentais como: coercitivo, autoritário, hiperenvolvido, permissivo, desligado e negligente, com influências negativas na saúde mental dos filhos. Ainda foram descritos como possíveis causas os "transtornos psiquiátricos parentais, criminalidade, baixa estima parental, estilo negativo e depressivo, imaturidade das defesas, pouca capacidade de adaptação, personalidade de abandono ou limítrofe" (MARCELLI; COHEN, 2010, p. 386).

Há também os comportamentos externalizantes que são caracterizados pela impulsividade, agressividade, agitação e posicionamento desafiador e os comportamentos internalizantes que acabam, muitas vezes, privando o indivíduo de relacionar-se com as pessoas do meio, mostrando atitudes que são marcadas, principalmente, pelo retraimento (BOLSONI-SILVA; MARTURANO et al, 2006).

Estudos tem relacionado estilos parentais como: coercitivo, autoritário, hiperenvolvido, permissivo, desligado e negligente, com influências negativas na saúde mental dos filhos. Ainda foram descritos como possíveis causas os "transtornos psiquiátricos parentais, criminalidade, baixa estima parental, estilo negativo e depressivo, imaturidade das 
defesas, pouca capacidade de adaptação, personalidade de abandono ou limítrofe" (MARCELLI; COHEN, 2010, p. 386).

As regras de convivência variam em cada cultura e de família para família. Por esse motivo, a criança precisa ser informada quais regras devem acontecer dentro daquela família, para que, dessa forma, fique mais fácil reconhecer quais são os seus limites. O meio em que a criança vive contribui na sua organização mental e na internalização desses limites (GORAYEB, 1985)

Frequentemente a palavra limites é associada à obediência, respeito e cidadania, podendo ser entendida como uma fronteira. Na educação, geralmente a palavra está associada ao que é permitido e proibido. É na família que são colocados os primeiros limites para a criança e os pais, por vezes, se mostram com dúvidas de como estabelecer limites para os filhos (LA TAILLE 1999 apud ARAUJO; SPERB, 2009)

Alguns fatores que podem interferir nos limites que os pais pretendem passar para os filhos é a culpa dos pais por ter agido de forma inadequada, colegas que podem influenciar no comportamento dos filhos, as próprias características individuais da criança, modismos e consumo (ARAUJO; SPERB, 2009).

As crianças quando nascem não sabem o que pode ser feito e o que não pode, não existe ainda uma consciência ética, as pessoas só dizem não para as coisas erradas, quando desde pequenos foram ensinadas que se pode fazer muitas coisas e que muitas outras não pode, mesmo que sintam muita vontade ou prazer naquilo e que, mesmo não podendo fazer algumas coisas, as pessoas são felizes assim, especialmente quando aprendem a se colocar no lugar e amar o próximo (ZAGURY, 2004).

Dentro deste contexto, a presente pesquisa teve como objetivo analisar a influência do modelo educacional parental sobre a criança na segunda infância; verificar se no modelo parental utilizado pela família há limites estabelecidos; se os pais já foram chamados na escola pelo comportamento do seu filho e se alguém na família já apresentou ou apresenta algum tipo de transtorno mental. A hipótese deste trabalho é que exista uma relação entre modelos de educação, psicopatologias parentais e o comportamento que a criança apresenta.

\section{MÉTODO}

Trata-se de um estudo de campo, descritivo e qualitativo. A amostra foi probabilística realizada por meio da técnica de amostra aleatória simples, ou casual. No momento da 
pesquisa tinha no Centro de Educação Infantil seis turmas do maternal e quatro turmas do préescolar, com 200 alunos ao total. Para selecionar a amostra, o pesquisador atribuiu um número para cada aluno e após fez um sorteio para identificar os $10 \%$ da amostra que participaram da pesquisa, caracterizando uma amostra de 20 alunos.

Após o sorteio, o pesquisador identificou os pais dos alunos sorteados, fez o contato com os mesmos para no primeiro momento convidar a fazer parte da pesquisa e depois marcar um horário para realizar a entrevista. A coleta de dados foi através de entrevista semiestruturada a qual foi realizada após a assinatura do Termo de Consentimento Livre e Esclarecido (TCLE) e a análise dos dados foi realizada através da análise de conteúdo. Importante ressaltar que esta pesquisa foi aprovada pelo Comitê de Ética em Pesquisa da UNESC e tem como número de parecer 1.561.473.

\section{ANÁLISE DOS RESULTADOS E DISCUSSÃo}

A amostra inicial desta pesquisa enquadraria vinte (20) pais. Entretanto, como 3 destes não aceitaram responder as entrevistas, houve-se uma perda amostral de $0,6 \%$.

Desta forma, realizou-se a pesquisa com dezesseis (16) mães e uma (1) avó.

As idades dos filhos e neto variaram de 3 a 5 anos, sendo 4 crianças com 5 anos, 2 com 4 anos e 11 com 3 anos de idade.

O número de filhos variou de 1 a 4 filhos, sendo que 5 entrevistadas possuem 1 filho, 8 entrevistadas possuem 2 filhos, 3 entrevistadas possuem 3 filhos e 1 entrevistada possui 4 filhos. Sobre o estado civil, 10 das 17 entrevistadas são casadas, 1 é divorciada e 6 possuem união estável. O tempo de casamento das participantes variou de 1 ano a 18 anos.

De acordo com os resultados desta pesquisa podemos observar que 7 das 17 entrevistadas já foram chamadas na escola pelo comportamento do seu filho, como por exemplo a entrevistada E-4: "por ele estar meio irritado, por bater nos colegas e não obedecer as professoras", e a E-15: "sim, por causa de mordidas, brigas e lutinha".

Na segunda infância a criança pode apresentar comportamentos internalizantes que são aqueles marcados pelo retraimento, ansiedade, depressão e também comportamentos externalizantes que são marcados pela impulsividade, agressão, agitação e características desafiantes sendo que este último acaba sendo mais frequente e tendem a diminuir com a idade, podendo ser considerados como fazendo parte do desenvolvimento normal das crianças. 
A queixa, muitas vezes, pode ser feita baseada no quanto essa criança incomoda e porque ela não está manifestando o comportamento esperado, o que não necessariamente quer dizer que está com algum problema ou transtorno (ASSUMPÇÃO, 2014).

Contudo, dependendo da intensidade do comportamento da criança e de como o ambiente no qual está inserida lida com esses comportamentos, seja em casa ou na escola, pode representar algum risco ao desenvolvimento, dificuldades no relacionamento com os colegas ou posterior problema de comportamento (BOLSONI-SILVA; MARTURANO et al, 2006).

A entrevistada E-17: "sim, a queixa foi que ele estava apresentando um comportamento sexual com as bonecas". O comportamento de uma criança não existe por si mesmo ele é fruto do relacionamento com outros adultos e crianças (CALLEGARO, 2004, apud REZENDE, 2013).

Quando as crianças brincam com bonecas, geralmente elas reproduzem o que costumam vivenciar e alguns dos seus comportamentos e atitudes são bastante parecidos com os de seus responsáveis que podem ser os pais, professores ou outros que tenham a responsabilidade de cuidar dessas crianças, um exemplo disso é quando estão brincando com bonecas e colocam as bonecas sentadas para assistirem a sua aula reproduzindo o que o professor faz. É através do faz de conta que a criança encara o mundo que vive, é através do imaginário que ela incorpora a cultura em que está inserida (ALTMANN; CARVALHO, 2012). Pode-se perceber que a cultura de cada criança difere em alguns aspectos, a cultura de cada família tem particularidades como acontecem com os valores, limites e regras.

As entrevistadas ao serem questionadas sobre a educação dos filhos e se havia limites e regras em casa, 14 entrevistadas responderam que sim e 3 entrevistadas de 17 disseram que não há limites e regras, por exemplo:

E-11: "sim há limites e regras, por exemplo, agora é hora do banho, hora de brincar, hora do almoço e se não quer comer porque não quer comer? e tem horário para dormir."

E-16: "sim alguns limites a gente tem que colocar, as regras são: se não obedecer não ganha o que quer, deixo de castigo e sem televisão."

As regras de convivência variam em cada cultura e de família para família. A criança precisa ser informada quais as regras devem acontecer dentro daquela família, para que possa reconhecer seus limites e estabelecer organização. 
Papalia e Feldman (2013) contribuem dizendo que há formas diferentes de disciplina, uma delas é intitulada como reforço e punição que acontece nos momentos em que a criança faz algo certo como guardar seus brinquedos ou ajudar a arrumar o seu quarto, por exemplo, e sua mãe o incentiva agradecendo com um sorriso gentil. Assim a criança entenderá que esse é um bom comportamento que deve ser repetido. Em algumas situações se fazem necessárias as punições, caso a criança faça algo como bater em um colega ou sair correndo em uma rua movimentada. Às vezes, é necessário usar o isolamento ou a negação de privilégios, esse método precisa ser administrado com calma e acompanhado de uma explicação simples com intuito de levar á obediência e não culpa, dessa forma poderá ter bons frutos.

Porém, para outras mães:

E-2 "é bem difícil ter regras lá em casa, eles respeitam mais a avó porque têm medo dela. Quando eu era casada havia muitas brigas, agora quero só agradar eles e não ficar brigando."

E-10: "não dou limite nenhum, ensino o que é certo e o que é errado, ela geralmente me obedece, mas não tenho regras estabelecidas. Pra maior eu já dou com a menor eu não dou porque ela não entende ainda então eu não dou regras. ",

Os fatores que mais interferem na falta de limites das crianças é a negligência e a falta de firmeza dos pais. Impor limites é uma questão complexa para os pais, muitas vezes, por querer agradar os filhos porque sentem que não ficam tempo suficiente com eles e, por esses motivos, acabam tirando do castigo e fazendo suas vontades (ALMASAN; ÁLVARO, 2006).

Das entrevistadas, 8 das 17 disseram que os filhos respeitam os limites e regras, 2 disseram que eles não respeitam e 7 disseram que geralmente eles respeitam, como exemplo temos: E-14: “sim, respeita, bem tranqüilo”, ,E-4: “quando é pra botar o sapato em dia de frio ele não coloca, não quer escovar os dentes, quando não é pra sair pra rua ele sai igual." E12: "tem vezes que sim, mas não é sempre, quando tem gente perto, ele não quer obedecer."

Estabelecer limites faz parte da educação, um processo que é fundamental para o convívio em sociedade, mas nota-se que existe muitas crianças e jovens com falta de limites atualmente, mostrando desrespeito com as regras e limites que lhe são solicitadas. Há nos pais, muitas vezes, medo de que as regras sejam injustas, medo de serem autoritários e que não consigam ser a autoridade onde as regras deveriam ser justas e bem explicadas (SANTOS; BARBOSA, 2007). 
As regras e limites são importantes para a criança se situar frente às situações que a vida irá proporcionar. Dessa forma, compreenderá o certo e o errado e, aos poucos, irão perceber que a sociedade de maneira geral, exige algumas regras, por isso, as crianças, precisam de limites desde o momento em que nascem. Estabelecer limites e criar rotina traz segurança para as crianças, mas sempre respeitando a individualidade de cada um (SILVA, 2011).

Os limites fazem parte da educação e do desenvolvimento das crianças. É de grande importância que ela cresça com limites firmes para controlar a sua espontaneidade e, com o passar dos anos, será natural para ela, fazendo parte da sua existência, tornando-se um adulto com um maior senso de responsabilidade ( SANTOS; BARBOSA, 2007).

Os pais devem deixar claro para os filhos quais serão as consequências das transgressões das regras, devem saber, também, que quem cumprir as regras e tiver um bom comportamento pode receber privilégios, elogios ou ainda recompensas e que quem não cumprir não receberá nada disso. Esse aprendizado é mais eficaz quando acontece de forma constante, principalmente, se forem empregados de forma justa e de acordo com as ações das crianças (SILVA, 2011).

Se os pais reconhecerem as atitudes corretas dos filhos, seja elogiando ou premiando, a criança entenderá que aquilo que ela faz que é correto poderá trazer prazer (ZAGURY, 2004).

Todas as entrevistadas, ao serem questionadas se achavam que o modelo de educação utilizado por elas influencia no comportamento futuro dos filhos, responderam que sim, como exemplo as seguintes falas:

E-1 "sim, pois educamos da melhor maneira possível, queremos que influencie de uma forma positiva de acordo com os valores que passamos como compartilhar o que temos com as pessoas. "

E-11 "sim, a gente tenta educar para que quando ele crescer vai fazer as coisas certas, não somos agressivos, explicamos o porquê das coisas, damos um bom exemplo e ele vai levar para a vida inteira.

Sobre a importância dos valores Porto e Tamayo (2006, p. 152) afirmam que: “A transmissão de valores é um processo necessário para a formação dos valores do indivíduo e para a socialização dos membros do grupo social", muito do conteúdo que os pais passam para o filho ele irá usar para construir os seus valores e conviver com as outras pessoas. 
Os modelos parentais podem influenciar de várias formas o desenvolvimento dos filhos até mesmo em como os filhos irão educar os seus filhos futuramente, como por exemplo, uma mãe que costuma conversar bastante com seu filho, é bem provável que ele também adotará esse método quando tiver os seus filhos (WEBER, 2004).

As participantes, ao serem questionadas sobre a presença de transtorno mental nos pais, uso de medicação e terapia, 15 disseram que não possuem nenhum tipo de transtorno, não fazem uso de medicação, também não fazem terapia e 2 entrevistadas disseram que apresentam transtorno mental, fazem uso de medicação e terapia, por exemplo:

E-3: “Sim, sim eu tenho depressão e transtorno bipolar e o meu marido precisa só que ele não aceita, vou pra terapia religiosamente e tomo medicação, venlafaxina e ácido valpróico, fico mais deprimida. ”

E-4: “Sim eu faço, tenho dupla personalidade, transtorno bipolar, em uma hora eu to lá em cima, em outra hora tola em baixo, faço terapia três vezes por semana, tomo coplomazepina, carpamazepina, fluxetina, donarem."

De acordo com o DSM-5 (ASSOCIAÇÃO AMERICANA DE PSIQUIATRIA, 2014) a depressão é caracterizada pelo humor deprimido, diminuição do interesse ou prazer nas atividades, perda ou ganho de peso, perda de energia, sentimentos de culpa ou inutilidade, dificuldades de pensar ou se concentrar, pensamentos recorrentes sobre a morte podendo ser medo de morrer ou pensamentos suicidas. Esses sintomas causam prejuízos para o individuo, como no meio social, laboral ou em outras áreas importantes para essas pessoas.

O transtorno de humor bipolar é caracterizado pela instabilidade no humor, com recorrências de episódios maníacos e depressivos ao longo da vida de uma pessoa. Os sintomas podem causar prejuízos significativos nas áreas social, profissional, familiar ou outras (ASSOCIAÇÃO AMERICANA DE PSIQUIATRIA, 2014).

Quando existe o transtorno mental na família, esta pode passar por várias mudanças, como na rotina ou em hábitos diários.Com o diagnóstico pode haver uma sobrecarga ou conflitos no sistema familiar. Muitas vezes o transtorno é crônico gerando sentimentos de descontrole e medo na família (PEREIRA; PEREIRA JR, 2003).

As entrevistadas também foram questionadas com a seguinte pergunta: "Você acha que o fato de um dos pais apresentarem transtorno mental influencia no comportamento do seu filho? "02 entrevistadas acham que não e 15 das 17 entrevistadas disseram que sim. 
E-3: "sim, não consigo dar limites, não consigo ter jogo de cintura e ela é medrosa e nervosa, o que pode ser consequência disso. "

E-4: “influencia, ele é irritado, ele grita e fecha as mãos, em casa ele grita, é agitado, é uma criança nervosa, ele bota a mão na boca morde a mão e avança na pessoa. "

E-7 "acho que sim, crescer com aquilo, eles se espelham na gente. "

Para Marcelli e Cohen (2010) está claro que a família tem um papel muito importante na vida da criança, tanto no desenvolvimento saudável, quanto no aparecimento das psicopatologias, a família, muitas vezes, aparece como o principal fator causador dessas condições.

A saúde mental das crianças está fortemente ligada com as influências ambientais que ela sofre. Muitos autores têm apontado os aspectos existentes no ambiente onde a criança vive como estando ligados a transtornos mentais infantis externalizantes e internalizantes (HALPERN; FIGUEIRAS, 2007).

Alguns estudos mostram que a depressão está associada a fatores que não contribuem para o desenvolvimento infantil: as crianças que possuem mães deprimidas são mais inseguras e podem apresentar dificuldades nas esferas comportamentais, cognitivas, emocionais e, ainda, desenvolver transtornos psicossociais na idade adulta (MENDES; LOUREIRO; CRIPPA, 2008).

Em outra pesquisa realizada por Pereira e Santos (2012) pôde-se perceber que as mães com depressão possuíam uma pobre competência nas práticas parentais, são menos responsivas e exigentes.

\section{CONSIDERAÇÕES FINAIS}

Diante desta pesquisa pôde-se compreender melhor a relação entre limites, modelos educacionais e psicopatologias parentais. Nesta amostra, 7 das 17 mães entrevistadas já haviam sido chamadas na escola por comportamentos inadequados de seus filhos. No caso dos limites, a grande maioria das mães, 14 destas, relatou que estabelecem limites e regras na vida de seus filhos sendo que os limites podem gerar alguns conflitos de aceitação por parte dos filhos, 8 das 17 mães disseram que os filhos respeitam; 2 disseram que não respeitam e as outras 7 disseram que não é sempre que eles respeitam os limites estabelecidos, o que quer dizer que este tema ainda gera alguma dificuldade não só em estabelecê-los, mas em como fazer com que as crianças entendam e respeitem os limites. 
Sobre os modelos parentais, de acordo com as entrevistas, todas as mães tinham a compreensão de que o modelo de educação adotado por elas influencia o comportamento dos filhos. As entrevistadas acreditam que os modelos que têm utilizado para educar seus filhos irão contribuir para que se tornem indivíduos melhores e responsáveis, sendo que cada família tem uma cultura diferente no que diz respeito aos modelos parentais, nos limites, nos valores, no uso do castigo físico, nas conversas com os filhos sobre o que podem ou não fazer. Importante colocar que as mães com transtorno mental diagnosticadas, acreditam que pode haver complicações para seus filhos em virtude do seu estado mental e relataram que têm dificuldades em colocar limites e regras e os filhos, na visão delas, têm um comportamento mais difícil.

Diante do exposto poderíamos pensar em estratégias de saúde mental dentro das escolas, no sentido de haver uma equipe multidisciplinar com o objetivo de fazer visitas domiciliares quando forem detectados sinais na criança a fim de prevenir um possível desajustamento social ou até mesmo uma psicopatologia futuramente. Neste caso, não apenas a criança seria "monitorada", mas também a sua família e caso haja necessidade indicar para os profissionais especializados para realizar atendimento.

\section{REFERÊNCIAS}

ALMASAN, Daisy Ariane; ÁlVARO, Alex Leandro Teixeira. A importância do senso de limites para o desenvolvimento da criança. Revista Científica Eletrônica de Psicologia, Garça, v. 4, n. 7, p. 01-07, ju/dez. 2006.

ALTMANN, Helena; CARVALHO, Gabriella Elaine Fagundes. Sexualidade na Educação Infantil: Entre o Silenciamento e a Vigilância. Revista Artifícios, Campinas, v. 2, n. 4, p 01-13, dez. 2012.

ASSOCIAÇÃO AMERICANA DE PSIQUIATRIA. DSM-5: Manual de diagnóstico e estatístico de transtornos mentais. 5. ed. Porto Alegre: Artmed. 2014. ISBN 9788582710883

ASSUMPÇÃO JUNIOR, Francisco Baptista et al. Psiquiatria da infância e da adolescência: casos clínicos. Porto Alegre: Artmed, 2014. ISBN 9788582710296.

ARAUJO, Greicy Boness; SPERB, Tania Mara. Crianças e a Construção de Limites: narrativas de mães e professoras. Psicologia em Estudo, Maringá, v.14, n. 1, p. 185194, jan./mar. 2009.

BEE, Helen. O Ciclo Vital. Porto Alegre: Artmed, 1997. ISBN 85-7307-181-8.

BOLSONI-SILVA, Alessandra Turini et al. Habilidades sociais e problemas de comportamento de pré-escolares: comparando avaliações de mães e de professoras. Psicologia, Reflexão e Crítica, [s.1.], v. 19, n. 3, p. 460-469, 2006. Disponível em: 
<http://www.scielo.br/scielo.php?script=sci_arttext\&pid=S0102-

79722006000300015> Acesso em: 3 set. 2016.

BONDIN, Isabel; OFFORD, David. Transtorno da conduta e comportamento anti-social. Revista Brasileira de Psiquiatria, São Paulo, v. 22, n. 2, p. 12-15, 2000. Disponível em: $\quad<$ http://www.scielo.br/scielo.php?script=sci_arttext\&pid=S151644462000000600004> Acesso em: 7 set. 2016.

CIA, Fabiana; WILLIAMS, Lúcia Cavalcante Albuquerque; AIELLO, Ana Lucia Rossito. Influências paternas no desenvolvimento infantil: revisão da literatura. Psicologia escolar e educacional, Campinas, v. 9, n. 2, p. 225-233, dez. 2005. Disponível em:<http://pepsic.bvsalud.org/scielo.php?script=sci_arttext\&pid=S1413 85572005000200005\&lng=pt\&nrm=iso>. acessos em: 24 ago. 2016.

CID, Maria Fernanda Barboza; MATSUKURA, Thelma Simões. Mães com transtorno mental e seus filhos: risco e desenvolvimento. O Mundo da Saúde, São Paulo, v. 34, n. 1, p.73-81, 2010. Disponível em: <http://www.saocamilosp.br/pdf/mundo_saude/74/09_original_Maes.pdf>Acesso em: 15 set. 2016.

GORAYEB, Raul. Temas básicos de psicologia. 16. ed. São Paulo: E.p.u, 1985.

GRUNSPUN, Haim. Crianças e adolescentes com transtornos psicológicos e do desenvolvimento. São Paulo: Atheneu, 1999. ISBN 8573791594.

MARCELLI, Daniel; COHEN, David. Infância e Psicopatologia. 8. ed. Porto Alegre: Artmed, 2010. ISBN 9788536323978

HALPERN, Ricardo; FIGUEIRAS, Consuelo de Melo. Influências ambientais na saúde mental da criança. Jornal de Pediatria, Porto Alegre, v. 80, n. 2, p. 104-110, 2007. Disponível em: <http://www.scielo.br/scielo.php?script=sci_arttext\&pid=S002175572004000300013>. Acesso em: 17 mar. 2016.

MENDES, Ana Vilela; LOUREIRO, Sonia Regina; CRIPPA, José Alexandre. Depressão materna e a saúde mental de escolares. Revista de Psiquiatria Clínica, Uberaba, v. 35, n. 5, p. 178-86, abr. 2008. Disponível em: <http://www.scielo.br/pdf/rpc/v35n5/a02v35n5.pdf> Acesso em: 17 set. 2016.

MICHELON, Leandro; VALLADA, Homero. Fatores genéticos e ambientais na manifestação do transtorno bipolar. Revista de Psiquiatria Clínica, São Paulo, v. 32, n. 1, p. 21-27, 2005. Disponível em: <http://www.scielo.br/pdf/rpc/v32s1/24408.pdf> Acesso em: 21 set. 2016.

PAPALIA, Diane E.; FELDMAN, Ruth Duskin. Desenvolvimento humano. 12. ed. Porto Alegre: Artmed, 2013. ISBN 9788580552164

PAPALIA, Diane E.; OLDS, Sally Wendkos; FELDMAN, Ruth Duskin.Desenvolvimento Humano. 8. ed. Porto Alegre: Artmed, 2006. ISBN 8536302089

PEREIRA, Lais de Toledo Krucken. Teorias do Desenvolvimento II: livro didático. 2. ed. Palhoça: Unisulvirtual, 2009. 236 p.

PEREIRA, Maria Alice Ornelas; PEREIRA JR. Alfredo. Transtorno mental: dificuldades enfrentadas pela família. Revista da Escola de Enfermagem USP, São Paulo, v. 37, n. 4, p. 92-100, dez. 2003. Disponível em: $<$ http://www.scielo.br/scielo.php?script=sci_arttext\&pid=S0080623420030004000 
11\&lng=pt\&nrm=iso>. acessos em: 30 ago. 2016. http://dx.doi.org/10.1590/S008062342003000400011.

PORTO, Juliana Barreiros; TAMAYO, Alvaro. Influência dos Valores Laborais dos Pais sobre os Valores Laborais dos Filhos. Revista Psicologia: Reflexão \&Crítica, Brasília,v.19, n. 1, p. 151-158, 2006. Disponível em: 〈http://www.scielo.br/pdf/\%0D/prc/v19n1/31304.pdf> Acesso em: 11 set. 2016.

PESCE, Renata Pires. Problemas de comportamento externalizantes na infância: A violência em foco. 2009. 123f. Tese (Doutorado em saúde pública) - Escola Nacional de Saúde Pública. Centro Latino Americano de Estudos de Violência e Saúde Jorge Careli ENSP -FIOCRUZ, Rio de Janeiro. Disponível em: $<$ http://www.arca.fiocruz.br/bitstream/icict/2592/1/ENSP_Tese_Pesce_Renata_Pires.p df> Acesso em: 13 de mar. 2016.

REZENDE, Maria Asturiano Campos. Da criança problema na educação infantil á criança como enigma: uma direção marcada pela psicanálise. 2013. 287f. Dissertação (Mestrado em educação) - Universidade de São Paulo, São Paulo, 2013. Disponível em:

<www.teses.usp.br/.../TANIA_MARIA_ASTURIANO_DE_CAMPOS_RE> Acesso em: 8 set. 2016.

RUZZI-PEREIRA, Andrea; SANTOS, Jair Lício. Doença Mental Materna, Estilos Parentais e Suporte Social - Estudo das Concepções de Mães e Adolescentes no Interior de São Paulo.Revista Brasileira do Desenvolvimento e Crescimento Humano, São Paulo, v. 22, n. 1, p. 73-80, 2012. Disponível em: <http://pepsic.bvsalud.org/pdf/rbcdh/v22n1/pt_11.pdf> Acesso em: 20 set. 2016.

SANTOS, Francine Marcéli Faria, BARBOSA, Ruth Machado. Reflexões Psicossociológicas sobre a Falta de Limites: Tematizando a Alteridade. Pesquisas e Práticas Psicossociais, São João Del-Rei, v. 1, n 2, p. 24-33, Mar./Ag. 2007. Disponível em: <http://www.ufsj.edu.br/portal-repositorio/File/revistalapip/4artigo.pdf $>$ Acesso em: 3 set. 2016.

SILVA, Silmara Ferreira Piedade. Regras e limites na formação da criança. 2011. $73 \mathrm{f}$. Monografia (Especialização em Desenvolvimento Humano, Educação e Inclusão Escolar) -Universidade de Brasília, Universidade Aberta do Brasil, Brasília, 2011. Disponível em:

<http://bdm.unb.br/handle/10483/2142> Acesso em: 3 set. 2016.

WEBER, Lidia Natalia Dobrianskyjet al. Identificação de Estilos Parentais: o ponto de vista dos pais e dos filhos. Psicologia, Reflexão e Crítica, Curitiba, v. 17, n. 3, p.323-331, 2004. Disponível em: 〈http://www.scielo.br/pdf/prc/v17n3/a05v17n3.pdf>. Acesso em: 5 mar. 2016.

ZAGURY, Tania. Limites sem trauma: construindo cidadãos. 62.ed. Rio de Janeiro: Record, 2004.ISBN 8501059943. 